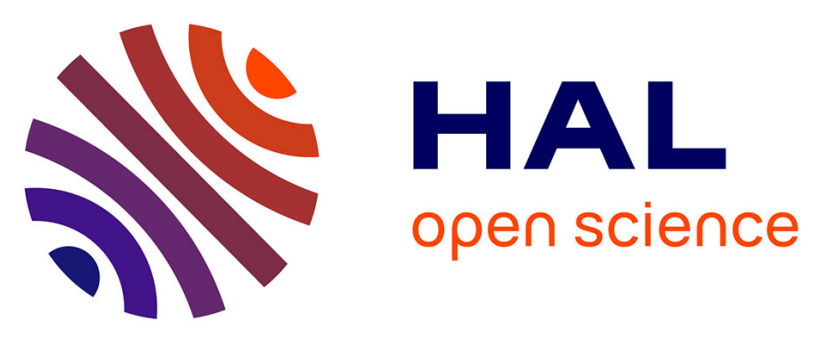

\title{
Broadband single mode SiGe graded waveguides with tight mode confinement for mid-infrared photonics
}

Joan Manel Ramírez, Vladyslav Vakarin, Mumtahina Rahman, Papichaya Chaisakul, Xavier Le Roux, Laurent Vivien, Delphine Marris-Morini, Daniel Chrastina, Jacopo Frigerio, Giovanni Isella

\section{To cite this version:}

Joan Manel Ramírez, Vladyslav Vakarin, Mumtahina Rahman, Papichaya Chaisakul, Xavier Le Roux, et al.. Broadband single mode SiGe graded waveguides with tight mode confinement for mid-infrared photonics. 18th Photonics North Conference, May 2016, Québec, Canada. hal-01322082

\section{HAL Id: hal-01322082 \\ https://hal.science/hal-01322082}

Submitted on 27 May 2016

HAL is a multi-disciplinary open access archive for the deposit and dissemination of scientific research documents, whether they are published or not. The documents may come from teaching and research institutions in France or abroad, or from public or private research centers.
L'archive ouverte pluridisciplinaire HAL, est destinée au dépôt et à la diffusion de documents scientifiques de niveau recherche, publiés ou non, émanant des établissements d'enseignement et de recherche français ou étrangers, des laboratoires publics ou privés. 


\section{Broadband single mode $\mathrm{SiGe}$ graded waveguides with tight mode confinement for mid-infrared photonics}

\author{
Joan Manel Ramírez, Vladyslav Vakarin, \\ Mumtahina Rahman, Papichaya Chaisakul, Xavier \\ Le Roux, Laurent Vivien, Delphine Marris-Morini \\ Institut d'Électronique Fondamentale \\ Université Paris Sud, CNRS, Université Paris Saclay \\ 91405 Orsay, France \\ e-mail: joan-manel.ramirez@u-psud.fr
}

\begin{abstract}
Graded $\mathrm{Si}_{1-\mathrm{x}} \mathrm{Ge}_{\mathrm{x}}$ waveguides with tight mode confinement in a broadband range of mid-infrared wavelengths are presented. Optimum TM mode confinement is observed due to the vertical variation of the refractive index. These waveguides show good potential for implementation as passive elements in mid-infrared optical circuits where strong mode confinement is required for a broadband range of wavelengths.
\end{abstract}

Keywords-mid-infrared; $S i_{1-x} G e_{x}$ waveguides; mode confinement; broad band single mode polarization

To date, Silicon photonics has proved to be an enabling platform that provides integrated low-cost solutions for several applications including biosensing, imaging, computing, alloptical signal processing or high speed data communications, among others [1]. However, and despite the large variety of works reported so far by worldwide research institutions, most of them only focus on a narrow window of operation wavelengths that spans from the visible range up to the near infrared, typically up to $1.55 \mu \mathrm{m}$. Thus, little exploration has been done in the mid-infrared range. Only lately, and especially since the commercialization of Quantum Cascade lasers, renewed interest has been triggered on integrated midinfrared photonics. Interestingly, many molecules have their fundamental vibrational modes in that wavelength range, which provides a promising scenario for the development of highly sensitive label-free mid-infrared sensors. In that line, a complete new set of light sources is also foreseen in this wavelength range by exploiting the non-linear properties in silicon-related materials. As a matter of fact, silicon has demonstrated to be a good material choice to accomplish such purpose, since it has a suitable nonlinear refractive index and is transparent up to $8 \mu \mathrm{m}$. Consequently, silicon waveguides showing supercontinuum generation or optical parametric oscillation have been already demonstrated [2,3]. Similarly, Ge and $\mathrm{Si}_{1-\mathrm{x}} \mathrm{Ge}_{\mathrm{x}}$ alloys have also been suggested as primary raw materials in mid-infrared photonic building blocks due to the extended transparency window up to $12 \mu \mathrm{m}$ and the highest third order susceptibility compared to silicon (at $5 \mu \mathrm{m} \chi_{111}^{3}$ is $10^{-18} \mathrm{~m}^{2} / \mathrm{V}^{2}$ for Ge whereas is $\chi_{111}^{3} \sim 2 \times 10^{-19} \mathrm{~m}^{2} / \mathrm{V}^{2}$ for $\mathrm{Si}$ ).

Therefore, in this work we propose $\mathrm{Si}_{\mathrm{x}} \mathrm{Ge}_{1-\mathrm{x}}$ graded waveguides as fundamental building blocks for mid-infrared photonics. For that, waveguides are patterned on the virtual $\mathrm{Si}_{1 \text { - }}$ ${ }_{x} \mathrm{Ge}_{\mathrm{x}}$ substrates directly, taking advantage of the good mode confinement provided in the vertical direction by the graded

\author{
Daniel Chrastina, Jacopo Frigerio, Giovanni Isella \\ L-NESS, Dipartimento di Fisica, Politecnico di Milano, \\ Polo di Como, Via Anzani 42, \\ I 22100 Como, Italy
}

refractive index. Tight mode confinement of the fundamental TM and TE modes is demonstrated for a broad range of midinfrared wavelengths.

Rib waveguides were defined in a virtual $\mathrm{Si}_{\mathrm{x}} \mathrm{Ge}_{1-\mathrm{x}}$ substrate $11 \mu \mathrm{m}$ thick with increasing Ge concentration up to $\mathrm{x}=0.79$, deposited over a crystalline $\mathrm{Si}$ substrate [4]. Waveguide geometry was varied accordingly to support single mode propagation along a broad range of wavelengths, i. e. from 2 $\mu \mathrm{m}$ to $11 \mu \mathrm{m}$ (see figure 1 ). Better mode confinement for wavelengths below $6.5 \mu \mathrm{m}$ (TE) and $9.5 \mu \mathrm{m}$ (TM) is obtained from the comparison between a $\mathrm{Si}_{0.21} \mathrm{Ge}_{0.79}$ graded waveguide and a Ge-on-Si waveguide with same width and etching depth. Remarkably, the influence of the graded index variation along the vertical direction provides higher mode confinement for TM polarization in the graded waveguide. These graded waveguides may be a fundamental building block for passive optical links for mid-infrared applications when combined with other active devices that require broadband strong mode confinement.

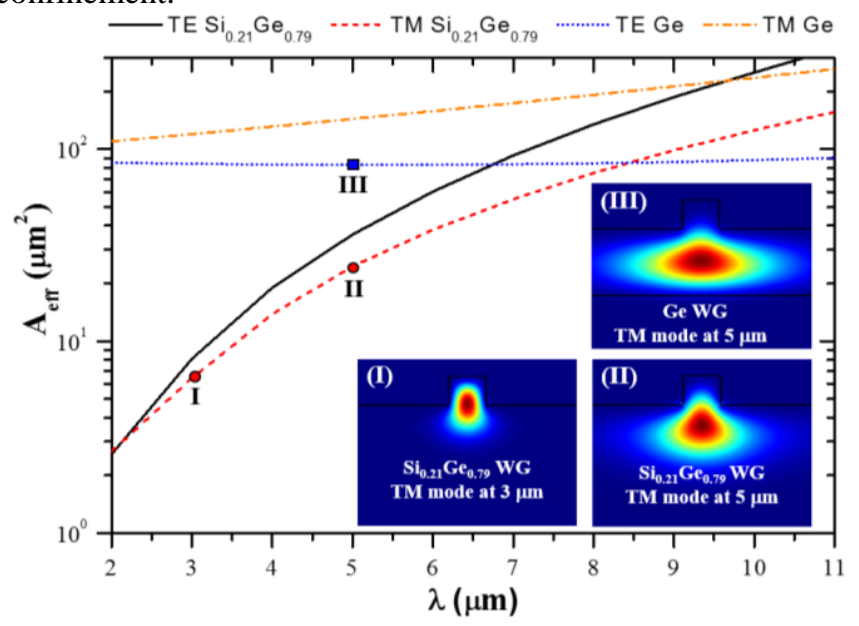

Figure: Effective modal area of fundamental TE and TM modes versus propagation wavelength for a $\mathrm{Si}_{1-\mathrm{x}} \mathrm{Ge}_{\mathrm{x}}$ waveguide (black straight line and red dashed line, respectively) and a Ge-on-Si waveguide (blue dotted line and orange dashed-dotted line). Insets I, II and III show the mode profile at selected wavelengths.

[1] R. Soref, Nature Photonics, 4(8), 495-497 (2010).

[2] B. Kuyken, et. al., Optics Express, 19(21), 20172-20181 (2011).

[3] X. Liu, et. al., Nature Photonics, 4(8), 557-560 (2010).

[4] V. Vakarin, et. al., Optics express, 23(24), 30821-30826 (2015). 
